\title{
Experimental Investigation of Contact Resistance Across Pressed Lead and Aluminum
}

by

A. C. Smith

Westinghouse Savannah River Company

Savannah River Site

Aiken, South Carolina 29808

L. L. Hamm

$\mathrm{X} . \mathrm{Ma}$

University of South Carolina

SC USA

J. Khan

University of South Carolina

SC USA

C. Rhodes

University of South Carolina

SC USA

A document prepared for ASME INTERNATIONAL MECHANICAL ENGINEERING CONFERENCE at Orlando, FL, USA from $11 / 5 / 2000-11 / 10 / 2000$.

DOE Contract No. DE-AC09-96SR18500

This paper was prepared in connection with work done under the above contract number with the U. S.

Department of Energy. By acceptance of this paper, the publisher and/or recipient acknowledges the U.S.

Government's right to retain a nonexclusive, royalty-free license in and to any copyright covering this paper, along with the right to reproduce and to authorize others to reproduce all or part of the copyrighted paper. 


\section{DISCLAIMER}

This report was prepared as an account of work sponsored by an agency of the United States Government. Neither the United States Government nor any agency thereof, nor any of their employees, makes any warranty, express or implied, or assumes any lègal liability or responsibility for the accuracy, completeness, or usefulness of any information, apparatus, product or process disclosed, or represents that its use would not infringe privately owned rights. Reference herein to any specific commercial product, process or service by trade name, trademark, manufacturer, or otherwise does not necessarily constitute or imply its endorsement, recommendation, or favoring by the United States Government or any agency thereof. The views and opinions of authors expressed herein do not necessarily state or reflect those of the United States Government or any agency thereof.

This report has been reproduced directly from the best available copy.

Available for sale to the public, in paper, from: U.S. Department of Commerce, National Technical Information Service, 5285 Port Royal Road, Springfield, VA 22161, phone: (800) 553-6847, fax: (703) 605-6900 email: orders@ntis.fedworld.gov online ordering: http://www.ntis.gov/ordering.htm

Available electronically at http://www.doe.gov/bridge Available for a processing fee to U.S. Department of Energy and its contractors, in paper, from: U.S. Department of Energy, Office of Scientific and Technical Information, P.O. Box 62, Oak Ridge, TN 37831-0062, phone: (865)576-8401, fax: (865)576-5728

email: reportseadonis.osti.gov 


\section{DISCLAIMER}

Portions of this document may be illegible in electronic image products. Images are produced from the best available original document. 


\title{
EXPERIMENTAL INVESTIGATION OF CONTACT RESISTANCE ACROSS PRESSED LEAD AND ALUMINUM CONTACT IN VACUUM ENVIRONMENT
}

\author{
Xiao Ma, Jamil A. Khan and Curtis A. Rhodes \\ Department of Mechanical Engineering \\ Laboratory for Applied Heat Transfer \\ University of South Carolina \\ Columbia, SC 29208 \\ Email: jamil.khan@sc.edu
}

\author{
Allen Smith and Luther E. Hamm \\ Westinghouse Savannah River Site \\ Aiken, SC \\ Email: Allen.smith@srs.gov
}

\section{ABSTRACT}

In the proposed production of Accelerator Production of Tritium (APT) blanket module, lead will be encased in aluminum cladding. Energy transfer rate from the lead to the cooling water will be a function of the contact resistance between lead and aluminum: No data for contact resistance for this application exists in the literature. An experimental investigation has been conducted to determine TCR between lead and aluminum in vacuum environment and also investigate the effect of pressure, surface roughness and interface temperature on the contact resistance.

The range of contact resistance is from $3.74 \times 10^{-4} \mathrm{~m}^{2} \mathrm{xK} /$ Watt to $11.45 \times 10^{-}$ ${ }^{4} \mathrm{~m}^{2} \mathrm{xK} /$ Watt. The contact resistance increases to be $168 \times 10^{-4} \mathrm{~m}^{2} \mathrm{xK} /$ Watt at small pressure. The contact resistance decreases with the increase in contact pressure. Interface temperature and surface roughness do not affect the contact resistance significantly. There is slight increase in contact conductance with increasing temperature. The experimental results are generally well within acceptable accuracy and the data should be a good reference for APT model.

\section{INTRODUCTION}

Heat flow through two contacting bodies is characterized by a temperature drop across the interface. The solid interface constitutes a resistance to heat flow. The resistance is called thermal contact resistance (TCR).

Thermal contact resistance is defined as the ratio of the temperature drop at an interface to the heat flow across the interface, i.e.

$$
R=\frac{\Delta T}{Q}[K / W a t t]
$$

where $\Delta T$ is the temperature drop across the interface, and $Q$ is the heat flow through the specimens. The contact resistance has sometimes been defined as the ration of the temperature drop to the heat flux across the interface, i.e.

$$
R^{\prime}=\frac{\Delta T}{q}=\frac{\Delta T \cdot A_{n}}{Q}\left[m^{2} K / \text { Watt }\right]
$$

In general, the heat transfer across the pressed solids interface can occur via three distinct modes: metal-to-metal conduction, radiate heat transfer, and interstitial material 
conduction. The heat transferred by the radiation across the interface remains small as long as the temperatures encountered are not too high. In the application of APT-blanket module, the heat transfer by radiation is often negligible. When the pressed solids contact is formed in a vacuum environment, the heat transferred by the interstitial material will not result the contact of the solids. Natural convection does not occur in this situation. The heat transferred by the conduction across the actual contact regions is the main concem. The thermal contact resistance varies mainly due to many undetermined distributed contact regions.

An experimental apparatus has been designed and constructed for the measurement of the thermal conduct resistance between lead and aluminum. Ten pairs of test specimens were used to determine thermal contact resistance. All aluminum specimens are 6061-T6 alloy and all lead specimens are $99.9856 \%$ lead. For the purpose of this research surfaces with different roughness were prepared. The specimens were pressed together in a vacuum. National Instrument Data Acquisition Board along with Lab view software was used to obtain the continuous data automatically during each experiment.

\section{EXPERIMENTAL PROGRAM}

The design of the test section is adopted from the test section used by Peterson and Fletcher [1] and McWaid and Marschall [2]. The thermal contact resistance was measured by passing a heat flux through two contacting cylindrical specimens. All experiments were performed in a vacuum chamber at a pressure less than $10^{-4} \mathrm{mbars}$ so as to prevent the transfer of heat across the interstitial gap by gaseous conduction. The vacuum environment ensured no radial heat lost due to convection. Additionally, the specimens were kept at relatively low temperature so that the radiative heat transfer across the interstitial gap was negligible. Low temperatures were also necessary to prevent excessive creep in lead, or complete melting of lead. The only significant mode of heat transfer across the interface was conduction through the solid contacts. Figure 1 below shows a layout of the test apparatus.

\section{Apparatus}

Vacuum System The vacuum chamber was made by Pyrex Bell Jar, which has a height of about $67 \mathrm{~cm}$ and an outside diameter of $46 \mathrm{~cm}$. The chamber sits onto a stainless steel base assembly containing the necessary thermocouples, electric power, compressed air and cooling liquid feed-throughs. A neoprene boot gasket was used at the bottom of the Bell Jar to form a hermetic seal between the chamber and the base, where as an added precaution Dow corning high vacuum grease was pasted to prevent leakage around the edge. The chamber was evacuated by using a turbo pump manufactured by BOC Edwards. The chamber pressure was monitored using an active Inverted Magnetron gauge and an active Pirani gauge. The two gauges were soldered to the stainless steel plate base, through where the chamber vacuum pressure was measured. A pressure of about $10^{-4}$ mbar was maintained during all tests.

Loading System The basic experimental setup consisted of the stacked column. A compressive force was exerted on the column by pneumatic actuator powered by compressed air. An air-inlet tube was connected to the air compress outside the chamber. An air pressure regulator was controlled the air pressure to the desired value. The

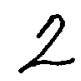




$$
\text { WSRC-TR-2000-00078 }
$$

compressed air is introduced at the top of the air cylinder. The piston inside the air cylinder was pushed to extend by the compressed air and this way the column was compressed. The air cylinder was mounted to a triangle plate, which was supported by three rods bolted to the stainless steel plate base. In order to avoid moments and lateral forces the compressive force was exerted on the column through a stainless steel ball bearing. The ball sat loosely in the ball cage. Since the ball was free to roll within the cage, it did not transfer moments or lateral forces to the column. The column underwent uniform normal compression. A miniature low profile calibrated load cell supplied by Transducer Techniques was used to determine the compressive pressure. It was connected to the bottom part of the ball cage and could measure up to $1000 \mathrm{lb}$.

Heat and Cooling System The temperatures of the specimens are controlled using circulating cooling water at the bottom and the heated at the top. A base connector was mounted on the stainless steel plate base to hold the cooling system. Cooper tubing was constructed in a coil around an aluminum cylinder, which was held by the connector. Cooling water from a constant temperature bath was re-circulated for extracting heat from the base of the specimens. Water, and ice and water were used as the coolant during all the experiments. A 1/35 horsepower chemical submersible centrifugal pump was used to pump the circulating water through the copper tubing. A $91.44 \mathrm{~cm}$-long flexible rope heater was wrapped around an aluminum cylinder to provide heat. Power was controlled by a percentage temperature controller. An insulator, fabricated out of Teflon, was used to minimize the amount of heat transfer up through the load cell, ball, ball cage and the air cylinder. Thus the thermal path downward through the specimens represents a much smaller thermal resistance than the thermal path upward. In order to ensure that onedimensional conduction did indeed occur, a radiation shield made out of aluminum alloy was carefully put around the specimens. The heat meter was fabricated from NIST Standard Reference Material (SRM) 1462 and was used in order to measure the actual heat flow rate through the column.

Temperature Measurement System The K Type thermocouples were used for all of the temperature measurements. $36 \mathrm{AWG}$ gauge and $30 \mathrm{AWG}$ gauge thermocouples were used in order to minimize conduction through the thermocouple lead, accurate specification of thermocouple location, and to minimize the disturbance of the heat flow. The thermocouples were mounted in holes drilled perpendicular to the axis of symmetry of the specimens and the heat meter. The thermocouples were mounted into the holes using high temperature and thermally conductive epoxy.

Specimen Preparation Each specimen was $7.62 \mathrm{~cm}$ long by $2.54 \mathrm{~cm}$ diameter. Three holes were drilled perpendicular to each specimen's axis of symmetry. The top hole was located $1.27 \mathrm{~cm}$ below the top surface. The remaining holes were located 2.54 $\mathrm{cm}$ and $5.08 \mathrm{~cm}$ respectively, below the top hole (except the first and second experiments, the top hole was located $1.905 \mathrm{~cm}$ below the top surface, the remaining holes were located $1.905 \mathrm{~cm}$ and $3.81 \mathrm{~cm}$ respectively, below the top hole.) Extreme care was taken during the preparation of the contacting surfaces. The surface roughness was measured by a high-resolution profilometer. Surface condition was prepared by machining, sandblasting and polishing. 


\section{WSRC-TR-2000-00078}

Data Acquisition System All the thermocouples were connected to a National Instrument Data Acquisition system through the feedthroughs. The National Instrument Data Acquisition system included a SCXI board and Lab view software, used for collecting and storing the data.

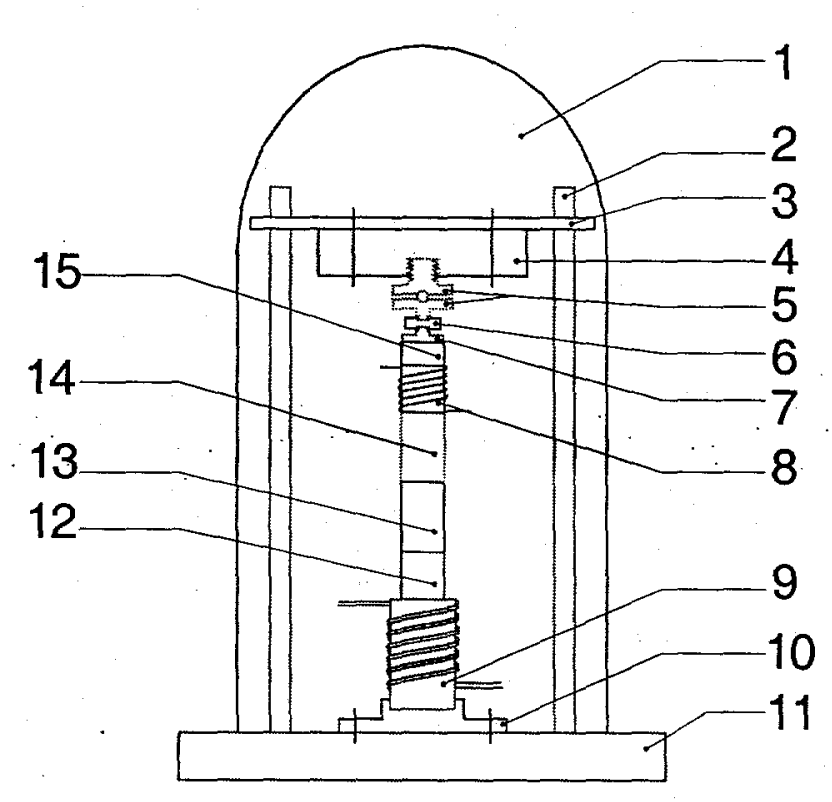

Figure1 Experiment Draft
1: Bell jar
2: Support rod
3: Triangle plate
4: Air cylinder
5: Ball cage
6: Loadcell
7: Connection part
8: Heater wrapping around
Aluminum piece
9: Cooling system
10: Connection part
11: Stainless Steel plate
12: Standard Reference
Material
13: Lead Specimen
14: Aluminum Specimen
15: Insulator

\section{Experimental Procedure}

Contact resistance data were obtained for pressure between 180psi and about 350psi. One of the experiments was conducted for a small pressure. Data were obtained for 180psi, 200psi, 250psi, 300psi and 350psi. For the first two experiments, contact resistance was obtained at one temperature under one pressure. From the third experiment, contact resistance was obtained at two different interface temperatures. At almost 100 degree Celsius interface temperature, the specimen were cycled through different pressures on the test column from 180psi to 350psi (data were taken every 50psi). After this pressure cycle, pressure was released and the specimens were returned to the original state. After several hours, power controller to the heater was changed in order to get almost 150 degree Celsius interface temperature. The specimen was then cycled through another pressure cycle as for 100 degree Celsius. The third experiment went to 200 degree Celsius for just 200psi and 250psi. For the eighth experiment, small pressure was applied for 100 degree Celsius and. 150 degree Celsius interface temperature, respectively. Due to the creep and deformation of the lead, the test column could not be held steady during all the experiments. During the third and the fourth experiments the specimen collapsed after exerting some pressure cycle and heating for long time. Eight or ten hours of actual testing were required to obtain the data for each pair of specimens at one state. The test column was allowed to reach steady state after each load change. Equilibrium was assumed to be reached when the measured temperature remained constant when over time, for at least 30 minutes. The assumption

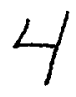




$$
\text { WSRC - TR-2000-00078 }
$$

of steady state corresponding to Antonetti and Eid [3] should not have introduced significant errors into the measurements.

Test Matrix See Table 1. 
Table 1 Experimental Test Matrix

\begin{tabular}{|c|c|c|c|c|c|}
\hline $\begin{array}{c}\text { Test No. } \\
(\text { date) }\end{array}$ & $\begin{array}{c}\text { Lead } \\
\text { surface }\end{array}$ & $\begin{array}{c}\text { Aluminum } \\
\text { surface }\end{array}$ & $\begin{array}{c}\text { Interface temperature } \\
\left({ }^{\circ} \mathbf{C}\right)\end{array}$ & $\begin{array}{c}\text { Interface pressure } \\
\text { (psi) }\end{array}$ & $\begin{array}{c}\text { Interface } \\
\text { fluid }\end{array}$ \\
\hline $1 .(6 / 11 / 98)$ & Machined & Machined & $\sim 155$ & $\sim 155$ & $\sim 155$ \\
\hline $2 .(6 / 16 / 98)$ & Polished & Sandblasted & $\sim 200$ & Vacuum \\
\hline $3 .(7 / 7 / 98)$ & Machined & Machined & $100,150,200$ & $180,200,250,300,350$ & Vacuum \\
\hline $4 .(7 / 20 / 98)$ & Sandblasted & Sandblasted & 100,150 & $180,200,250,300,350$ & Vacuum \\
\hline $5 .(8 / 4 / 98)$ & Polished & Polished & 100,150 & $180,200,250,300,350$ & Vacuum \\
\hline $6 .(10 / 15 / 98)$ & Machined & Machined & 100 & 180 \\
\hline $7 .(11 / 13 / 98)$ & Machined & Machined & 100,150 & $180,200,250,300,350$ & Vacuum \\
\hline $8 .(12 / 02 / 98)$ & Machined & Machined & 100,150 & Small pressure & Vacuum \\
\hline $9 .(3 / 30 / 99)$ & Machined & Machined & 100 & $120,180,250,300,350$ & Vacuum \\
\hline $10 .(5 / 11 / 99)$ & Machined & Machined & 150 & $150,200,250,300$ & Vacuum \\
\hline
\end{tabular}




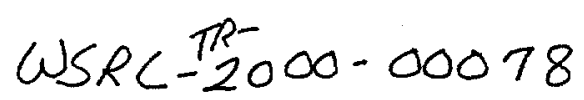

\section{RESULTS AND DISCUSSION}

The range of thermal contact resistance is from $3.74 \times 10^{-4} \sim 11.45 \times 10^{-4} \mathrm{~m}^{2} \times K / W a t t$.

Effect of Pressure and Interface Temperature To see the effect of pressure on the thermal contact resistance between lead and aluminum contact, six pairs of experiments were selected to present the thermal contact resistance versus pressure in Figure 2 through Figure 7. In each figure, thermal contact resistance was presented for the same pair specimen. It is obvious that the contact resistance decreases with the increasing in pressure at the same interface temperature. The variation of thermal contact resistance is from $4.94 \times 10^{-4} \sim 11.43 \times 10^{-4} \mathrm{~m}^{2} \times \mathrm{K} /$ Watt in the pressure range studied. Compare to magnesium and aluminum, the variation in the contact resistance is relatively higher in magnitude for the small range of pressure from $150 \mathrm{psi}$ to $350 \mathrm{psi}$. It is also shown that the effect of interface temperature on the contact resistance in Figure 2 through Figure 5 according to the specific experiment procedure. Data was obtained over pressure cycle at 100 degree Celsius and then at 150 or higher degree Celsius. The contact resistance decreased with the increasing interface temperature at the same pressure for the same pair of specimen. The variation in magnitude is not significant. But this trend is doubtable since the contact resistance doesn't decrease with the increasing interface temperature in Figure 6 and Figure 7 (both machined-machined specimens at different interface temperature).

Effect of Surface Roughness Comparing Figure 6.1, 6.2 and 6.3 for different surface roughness, for the roughness studied, the contact resistance showed no apparent relation between different surfaces. This is different from what was studied before: the contact resistance may be reduced by reducing the roughness of the mating surfaces. The surface roughness for these kind of dissimilar metals was found to be of secondary importance.

Effect of Time It could be seen that the contact resistance remains almost the same at around $5.18 \times 10^{-4} \mathrm{~m}^{2} \times \mathrm{K} / \mathrm{W}$ att during the long-term experiment from Figure 8 . Time has little effect on the contact resistance after it was established between two surfaces.

Effect of Small Pressure The thermal contact resistance is changed to be $168 \times 10^{-}$ $4 \mathrm{~m}^{2} \mathrm{xK} / \mathrm{W}$ att at small/no external pressure. To compare with the maximum data $11.45 \times 10^{-4} \mathrm{~m}^{2} \mathrm{xK} / \mathrm{Watt}$ got at $165 \mathrm{psi}$ and other experiment data, it could be seen that the magnitude of contact resistance increases in one order at small/no external pressure.

In this study, some limitations may affect the experimental results. Since no exactly the same study or previous work was done, no analytical correlation was developed to estimate these two dissimilar materials, the comparison with other work is limited to conclude suitable results. And also due to no prior information about the actual deformation of lead creep, for some cases, the creep was so large that the whole experimental specimen collapsed. This lead to some experiments terminated abnormally.

Although the high-resolution profilometer was used to get the surface roughness, it is still seen that the surface roughness has some conflicts between measurement and real surface preparation by defining machined, polished and sandblasted.

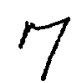




$$
\text { WSRC - TR-2000-00078 }
$$

Basically, these experimental data should be a good reference to investigate the energy transfer rate from the lead to the cooling water in APT model. Besides, there are more opportunities available for exploring the thermal contact resistance between dissimilar materials.

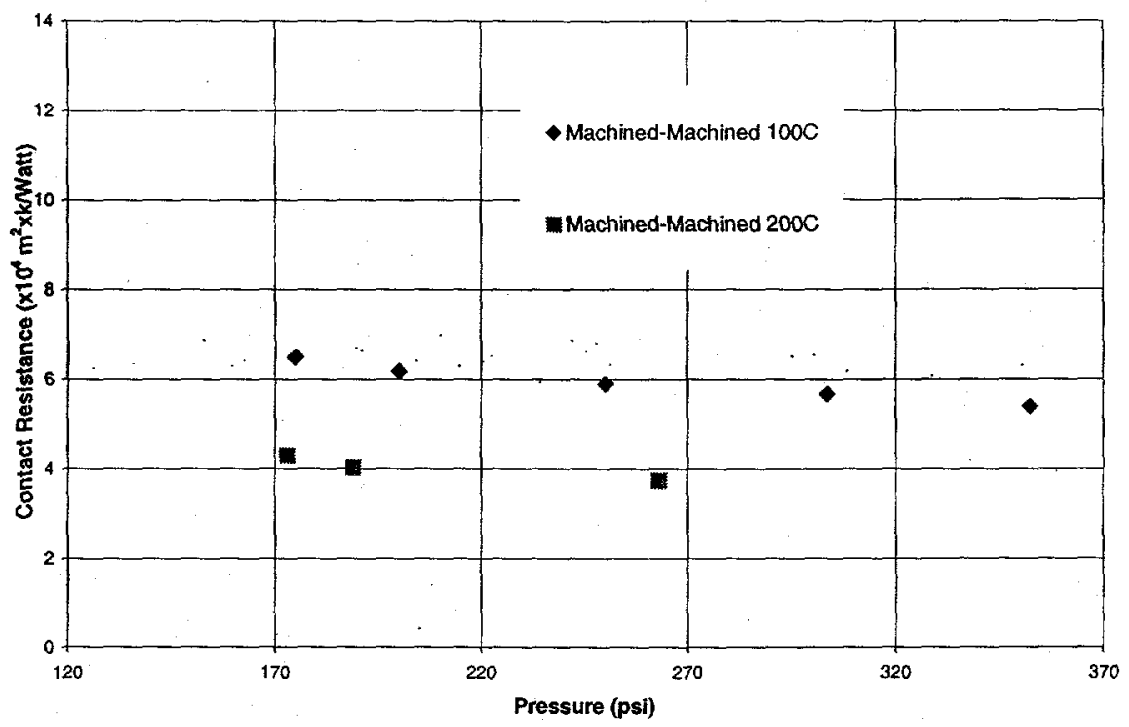

Figure 2 Thermal Contact Resistance vs. Pressure (3rd Experiment)

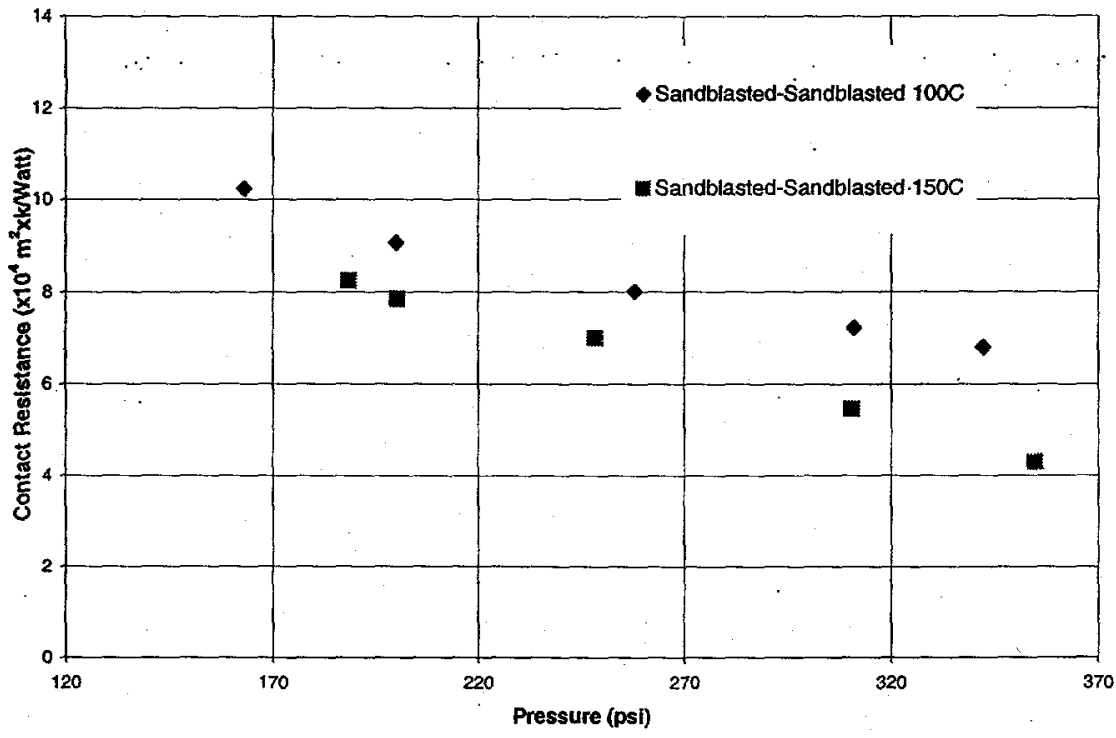

Figure 3 Thermal Contact Resistance vs. Pressure (4th Experiment) 


$$
\omega S R C-T R-2000-00078
$$

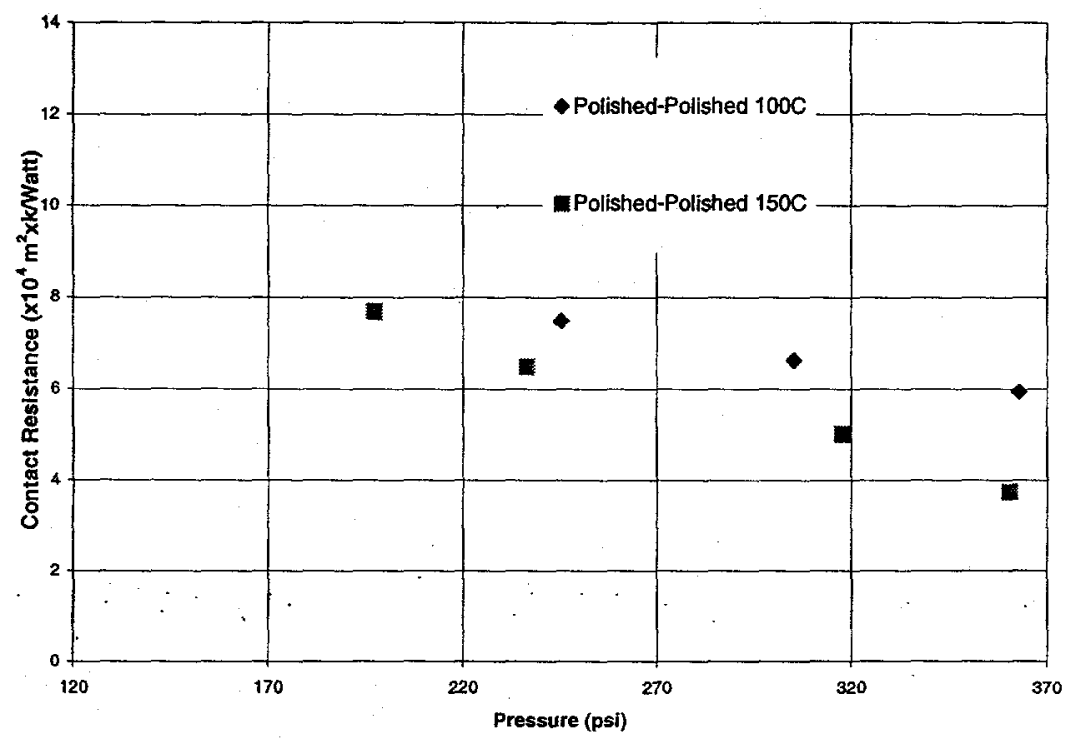

Figure 4 Thermal Contact Resistance vs. Pressure (5th Experiment)

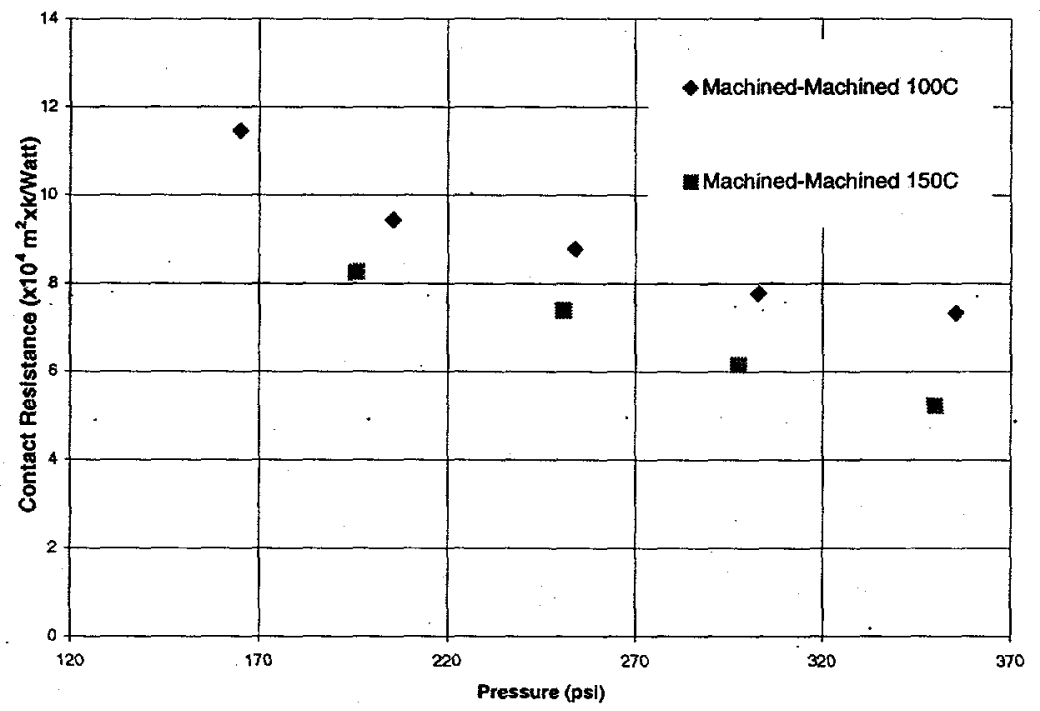

Figure 5 Thermal Contact Resistance vs. Pressure (7th Experiment) 


$$
\text { WSRC-TR-2000-00078 }
$$

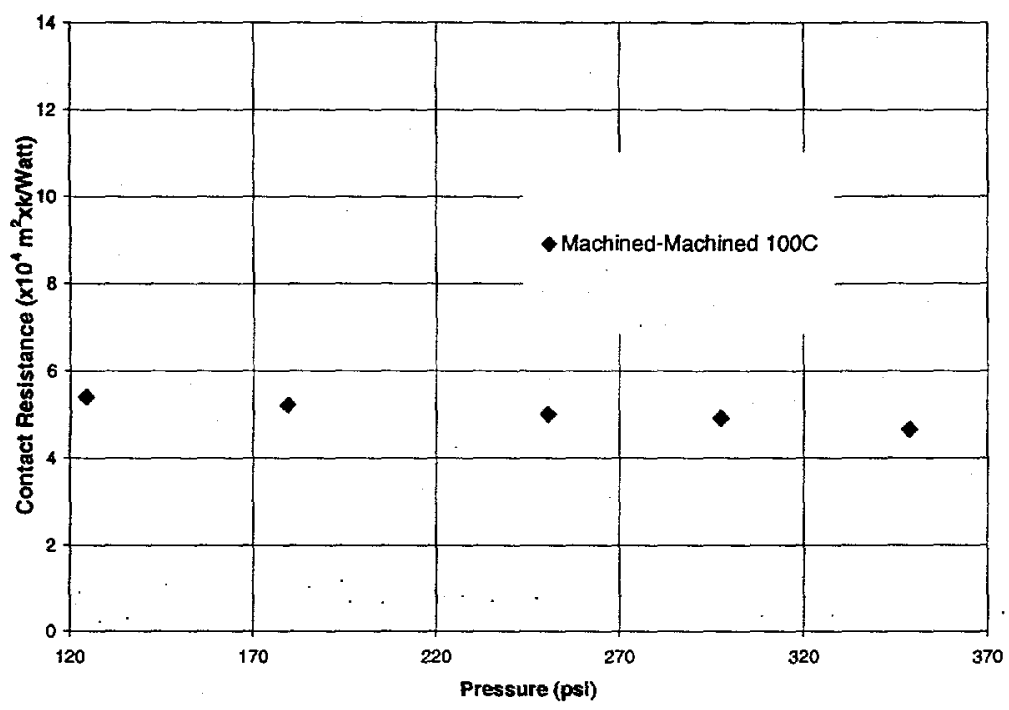

Figure 6 Thermal Contact Resistance vs. Pressure (9th Experiment)

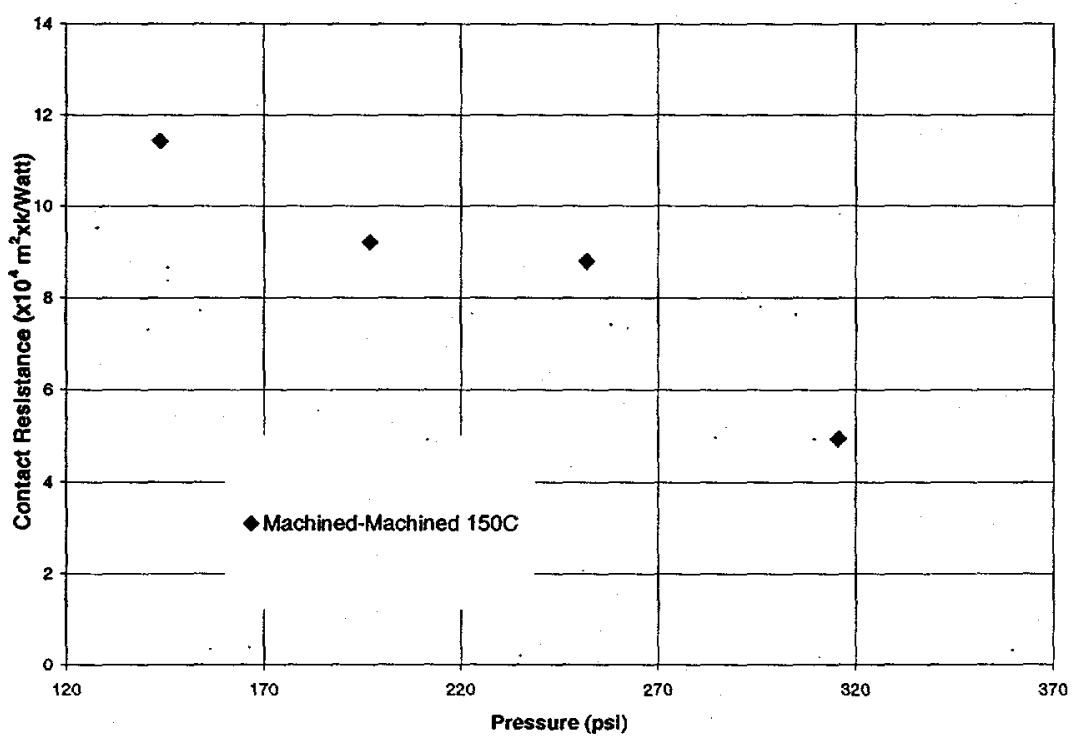

Figure 7 Thermal Contact Resistance vs. Pressure (10th Experiment) 


$$
\omega S R C-T R-2000-00078
$$

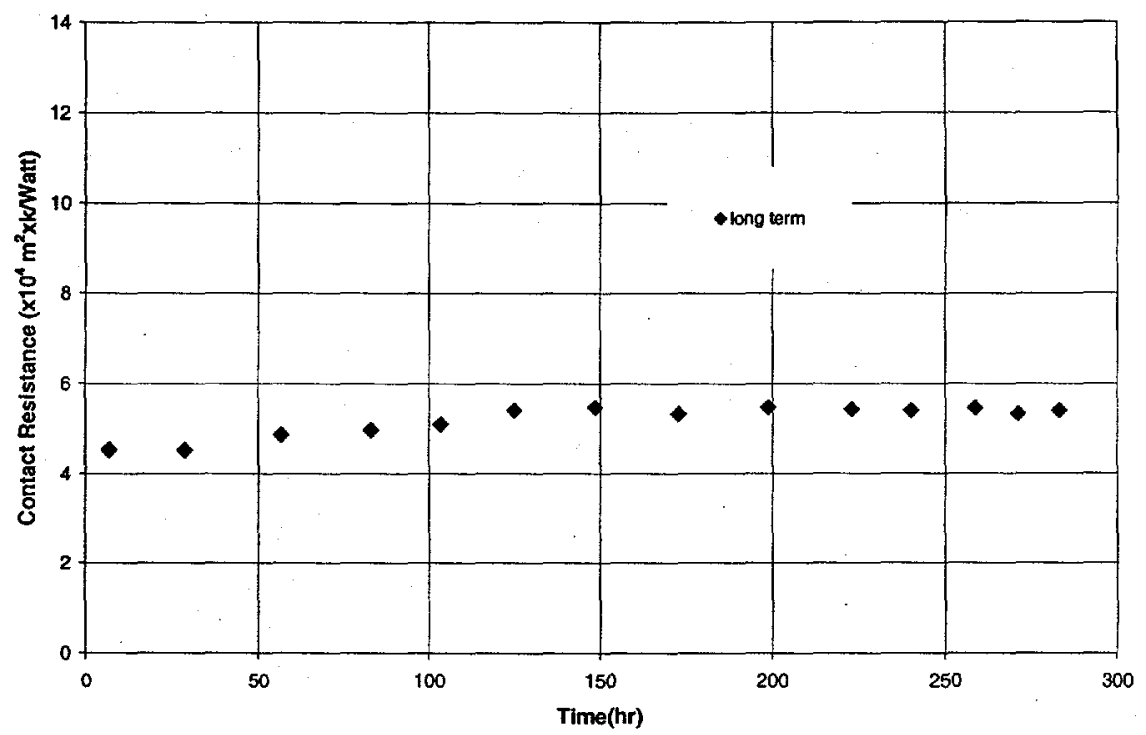

Figure 8 Thermal Contact Resistance vs. Time (6th Experiment)

\section{REFERENCES}

[1] Peterson, G.P. and Fletcher, L.S., "Measurement of the Thermal Contact Conductance and Thermal Conductivity of Anodized Aluminum Coatings", ASME Journal of Heat Transfer, Vol. 112, pp. 579-585, 1990.

[2] McWaid, T. and Marschall, E., "Thermal Contact Resistance Across Pressed Metal Contacts in a Vacuum Environment", International Journal of Heat and Mass Transfer, Vol. 35, No. 11, pp.2911-2920, 1992.

[3] Antonetti, V.W. and Eid, J.C., "A Technique for making Rapid Thermal Contact Resistance Measurements", Proceedings of the International Symposium on Cooling Technology for Electronic Equipment, Honolulu, HT, pp.449-460, Mar. 1987. 